\title{
Cloud Computing:
}

\section{A Systematic Literature Review and Future Agenda}

\author{
Mine Omurgonulsen, Hacettepe University, Turkey \\ Merve Ibis, Baskent University, Turkey \\ Yigit Kazancoglu and http, Yasar University, Turkey \\ Pretty Singla, Shree Ganesh Polytechnic, India
}

\begin{abstract}
Global competition has extended the scope of trade and extended the supply chains causing information management to be an essential part of business. Many new technologies have recently been adapted by organizations in the era of digitalization. Cloud computing has an important place in these technologies and has been integrated widely. In recent days, unexpected and risky periods such as the global pandemic increased the interest towards cloud computing both academically and practically. The purpose of this study is to analyze and classify the contributions of the studies published in the cloud computing field. The cloud literature is analyzed systematically from the management and business points of view. The review is limited to journal articles and papers published between 2014 and 2019. This research summarizes the current research attempts, discovers the research gaps, and provides a research agenda for future research on cloud computing within the context of information management in business and management from a global perspective.
\end{abstract}

\section{KEYWORDS}

Cloud Computing, Management, Research Agenda, Systematic Literature Review

\section{INTRODUCTION}

Many new technologies (e.g., Augmented Reality, Internet of Things, 3D Printers, Big Data, Cloud Computing, System Integration, etc.) have been widely used with the release of Industry 4.0. Industry 4.0 (Fourth Industrial Revolution) is defined as a production system based on cyber-physical systems (Kagermann et al., 2013). The integration of machines and objects, together with the Internet of Things technologies, has resulted in a huge amount of data. Collecting and analyzing this data will provide a competitive advantage for companies (Deloitte, 2015).

Cloud Computing is a new technology that could potentially revolutionize IT implementation and delivery (Alismaili et al., 2020). It is a model that can provide on-demand network access to configurable computing resources from a shared pool with minimal management effort or service provider interaction (Mell \& Grance, 2009). Service providers are divided into three classes according to the service offered, such as PaaS, SaaS, and IaaS (Rimal et al., 2011).

SaaS is a software delivery model where software is hosted locally and delivered over the Internet, and the payment method follows a subscription model (MCSI, MIETE, 2009). Performance is an important feature depending on the quality of SaaS (Wang \& Ying, 2018). Some SaaS applications

DOI: 10.4018/JGIM.20211101.oa40

This article published as an Open Access article distributed under the terms of the Creative Commons Attribution License (http://creativecommons.org/licenses/by/4.0/) which permits unrestricted use, distribution, and production in any medium, provided the author of the original work and original publication source are properly credited. 
have been developed for business technologies. This includes sales management, CRM, financial management, Human Resources Management. The second core service model PaaS provides developers with a platform that covers the developing, testing, distributing, and hosting lifecycle of advanced web applications as a service. Facebook F8, Salesforge App Exchange, Google AppEngine, Bunzee connect and Amazon C2 provides several ready-made services. This may indicate that PaaS can support multiple applications on a single platform (Xu, 2012). Finally, the most basic service of cloud computing is IaaS. The IaaS can be defined as the idea of purchasing IT hardware as a payas-you-go (post-pay).

Companies can create and maintain a tremendous competitive advantage through innovation. It is therefore not surprising that firms are highly concerned with the mechanisms that enable effective innovation (Chen et al.,2020). Cloud computing technologies can have businesses or individual users for different purposes (Chen et al., 2011). A cloud computing system holds critical data on the internet and provides users access wherever there is internet access (Durao et al., 2014). Many companies or users can use cloud systems for data storage and backup to save capital and infrastructure costs. Dropbox, Google Drive and Amazon S3 are of cloud computing solutions (Borodako et al., 2021). ERP and CRM are cloud computing business management applications. Cloud computing enables data scientists to analyze data, find correlations, predict future crises, and assist data-driven decisionmaking in an enterprise.

In today's developing world, cloud computing continues to be more widely adopted by companies. The adoption of cloud-based services can help organizations ensure a seamless and timely flow of information (Lal \& Bharadwaj, 2020). Despite some adverse effects of the global Covid-19 pandemic, the cloud computing market maintained its growth potential. This crisis has affected organizations globally. The vast majority of organizations had to adopt new ways of working styles with the pandemic. Deloitte has interviewed with CIOs from different sectors and it was seen that cloud computing adoption is one of the key trends in organizations' long-term priorities for CIOs. According to another research conducted by IBM and MC Kinsey, cloud investments will exceed traditional IT investments in 2020. In the study, it was seen that $94 \%$ of the participating companies used multiple cloud environments. This situation has raised some priority concerns (movement and connectivity among clouds, consistency of management) for organizations (Gagic et al., 2019).

Cloud computing has become one of the most demanded and studied topics. As mentioned above, some uncertain and crisis periods have increased the interest in cloud computing for organizations in recent years. Especially, the globalization of world trade widened the use of electronic trade and extended the supply chain networks drastically. Hence, the accumulation of data has been reached to significant amounts resulting from the need for an effective information management. Thus, the digitization of business increased the importance of information management for business. Moreover, the internet of things and Industry 4.0 has become essential for companies to achieve competitive advantages. As a result, cloud computing is arising as a cornerstone for these companies to build their information structure on. Therefore, cloud computing is becoming a crucial topic for businesses and management in a global context that can enable them to reach their targets.

Although there was a great deal of research in the period of 2014-2019 covering many different aspects of cloud computing, the maximum number of studies focused on cloud computing adoption and security. It is one of the most important steps for organizations to pay attention to their risks and make wise decisions to ensure the sustainability of adoption. This shows that why most of the researchers focus on the adoption and security issues of cloud computing in their studies.

According to Hanafizadeh \& Zareravasan (2020)'s SLR study during the period between 2011 and 2018, cloud computing has been the most studied outsourcing strategy. Borodako et al. (2021) stated in their study that cloud services are gaining popularity in current business environments and emphasized the importance of using "cloud" (cloud data) in teamwork and brainstorming. However, studies and their contributions on this subject in the literature have not been widely examined. The purpose of this study is to examine and categorize the cloud computing studies from the business point 
of view. Through this way, cloud computing and its application areas can be understood better. Also, we aim to reveal the literature gap, tendencies, interest and identify the research opportunities. Our study also offers a detailed overview of the cloud computing literature in terms of business context. We present some advantageous statistics, such as most studied sub-areas, top journals that publish cloud computing studies and top institutions. Similar researches have been studied for Industry 4.0 and its sub-component Internet of Things (see. Piccarozzi et al., 2018; Lu et al., 2018). This is the first study to present a detailed systematic literature analysis for the business aspect of the cloud computing literature between the years 2014 and 2019. The three research sub-questions for this detailed analysis that we aim to do are as follows:

RQ1. What are the enabling features of Cloud Computing?

RQ2. Who is working on the cloud computing and when?

RQ3. What are the current research attempts, literature gap and future directions?

There exist review studies with various scopes (e.g., security, adoption, supply chain, education, and SMEs) in the field of cloud computing. As distinct from the previous review papers, our study focused more generally on business and managerial aspects of cloud computing and analyzed the results. Descriptive analysis was conducted to make inferences about the future of cloud computing.

Meanwhile, as a result of the analysis, it has been seen that adoption and technology acceptance are the most studied subjects. When cloud computing studies are examined according to research areas in general business terms, it has been determined that finance and accounting are very popular areas. Especially investment, budgeting, and pricing issues have been studied a lot. When we look at the field of production and operations management, it is seen that the most studied subject is the supply chain, which shows that cloud computing integration in supply chains can help managers to observe, plan and evaluate supply chain processes. Similarly, in the field of organization and management, human resource management is getting a lot of attention, and therefore, understanding digital skills and information communication technology embedded in human resources is crucial to cloud adoption.

The findings of this study can contribute to businesses striving to integrate cloud computing. Therefore, the outputs of this study can serve as a guide for managers and researchers, especially from a management perspective. So, this study can support the efforts of business people to strengthen the competitive advantages of their companies through cloud computing. Furthermore, this literature review is thought to inspire enterprises and managers that would like to use cloud computing in terms of the scope, solution methods, factors, dimensions, and the results achieved in a holistic view.

This article is organized as follows. In Section 2, the literature review studies on cloud computing have been analyzed. In Section 3, basic review principles, review methodology and data collection are presented. In Section 4, the results of the study about each research question are discussed and illustrated. Section 5 concludes the paper and highlights the direction for the future research.

\section{LITERATURE REVIEW}

There are some review studies on cloud computing technologies, which can be divided into narrative and SLR. The narrative literature review studies focus on the semantic features of papers, while SLR studies focus on quantitative and reproducible elements of papers.

One of the benefits to conduct a SLR is that this method provides a straightforward structure of literature (Pickering \& Jason, 2014). Literature reviews are important to identify hypotheses, research topics and research questions and propose methodologies that may be useful for further researches (Rowley \& Slack, 2004).

Table 1 summarizes the basic literature review papers on cloud computing technologies and their purposes. There are 28 studies that review the Cloud Computing Systems literature. 20 of these studies conducted SLR method. The vast majority of these studies have focused on a specific subject of cloud 
computing and searched the literature, such as, structural equation modeling in cloud computing (Pisirir et al., 2019), supply chain integration (Novais et al., 2019), cloud computing adoption in developing countries (Mrhaouarh et al., 2018), cloud computing service composition (Jula et al., 2014), open source cloud simulation platforms and types (Lynn et al., 2016), applying semantic technologies in cloud computing (Brabra et al., 2016), resource scheduling and security in cloud computing (Sheikh et al., 2019), penetration testing in Mobile Cloud Computing apps (Al-Ahmad et al., 2019).

Some literature review studies focus on some specific managerial topics in cloud computing. For instance, cloud computing implication on service requirements (Benslimane et al., 2014), decisions related to cloud computing from the business point of view (Karunakaran et al., 2015), cloud computing and supply chain management (Jede \& Teuteberg, 2015; Novais et al., 2019), computing adoption (Alsaeed \& Saleh, 2015; Ibrahim \& Hemayed, 2015; Salleh et al., 2018; Mrhaouarh et al., 2018; Mohammed Banu et al., 2018 ), cloud computing and SMEs (Salleh et al., 2018; Pisirir et al., 2019).

The discussion of cloud technologies in business and management context is limited in the literature. Karunakaran et al. (2015) examined cloud computing technologies in terms of business and managerial perspective, but this study only deal with the papers till 2014. However, a great majority of the studies about cloud computing in the literature were published after 2014 and there has been no systematic literature analysis that deals with cloud computing in terms of business context since 2014. This study aims to review the state-of-art literature of cloud computing field from business perspective and to illustrate future research opportunities.

\section{METHODOLOGY}

There are some studies to provide a guideline to conduct a systematic literature review (Pickering \& Jason, 2014; Okoli \& Schabram, 2010). Those are discussed in the following sections.

\subsection{Included and Excluded Criteria}

The explanations about which studies will be included or excluded based on the criteria to be reviewed are summarized in Table 2. As can be seen in Table 2, inclusion and exclusion criteria divide into four main subsets can be seen in Table 2 .

\subsection{Methodology}

In this study, a systematic literature review was conducted using quantitative and qualitative research methods. The flow chart that we used in this study in Figure 1 was adopted from Garza-Reyes (2015) to identify the different stages of the SLR (Moher et al., 2009). The stages of the Systematic Literature research are shown in Figure 1 in a flow chart.

\subsubsection{Collection of Papers}

The collection of the paper process was explained in four phases (Table 3.). In general, Step one shows the first keyword search in different databases, Step 2 and Step 3 show the results with our research restrictions and Step 4 shows the results after duplications and were refined by included and excluded criteria.

The research of the articles was done by using the keyword "Cloud Computing" in Web of Science, Scopus and Science Direct databases (Step 1.). Business, Operations Research and Management Science, Management and Economics categories were used in the Web of Science database. In Scopus and Science Direct databases, it was limited to Business, Management and Accounting categories (Step 2.). All searches were restricted in title, in English and the years after 2014 were taken into consideration. Book chapters, books and conference articles were not included in the search (Step 3.).

After the duplicated articles were excluded, the remaining articles were analyzed by reading only the titles and abstracts. The articles that were repeated in the first short review process were 
Table 1. Cloud Computing Literature Review Studies Summary

\begin{tabular}{|c|c|c|c|}
\hline Author and Year & Research Focus & $\begin{array}{l}\text { Research } \\
\text { Type }\end{array}$ & No. of Papers \\
\hline Jula et al., 2014 & $\begin{array}{l}\text { This study focused on all reliable and } \\
\text { effective studies that have examined } \\
\text { Cloud Computing Service Composition. }\end{array}$ & SLR & NA \\
\hline Benslimane et al., 2014 & $\begin{array}{l}\text { The aim of this study was cloud } \\
\text { computing challenges and opportunities } \\
\text { and applications on service requirements } \\
\text { were discussed. }\end{array}$ & SLR & 132 \\
\hline Pfarr et al., 2014 & $\begin{array}{c}\text { This study was about the profile of the } \\
\text { academic cloud computing literature } \\
\text { in terms of data protection and data } \\
\text { privacy. }\end{array}$ & LR & 33 \\
\hline $\begin{array}{l}\text { Karunakaran et al., } \\
2015\end{array}$ & $\begin{array}{l}\text { The decisions related to cloud computing } \\
\text { in business aspect were examined. }\end{array}$ & SLR & 155 \\
\hline Müller et al., 2015 & $\begin{array}{l}\text { By synthesizing the existing literature, } \\
\text { it was aimed to determine the levels } \\
\text { of cloud computing advantages and } \\
\text { suggested applications on how to realize } \\
\text { these benefits. }\end{array}$ & SLR & 47 \\
\hline Lehrig et al., 2015 & $\begin{array}{l}\text { Existing definitions and metrics were } \\
\text { analyzed from the point of cloud } \\
\text { consumers and cloud providers. }\end{array}$ & SLR & 20 \\
\hline Alsaeed \& Saleh, 2015 & $\begin{array}{c}\text { This study reviewed the literature on } \\
\text { cloud computing adoption by higher } \\
\text { education. }\end{array}$ & SLR & 133 \\
\hline Jede \& Teuteberg, 2015 & $\begin{array}{l}\text { Existing researches on Cloud Computing } \\
\text { and Supply Chain Management were } \\
\text { analyzed and research gaps in the } \\
\text { literature have been reviewed. }\end{array}$ & SLR & 99 \\
\hline $\begin{array}{l}\text { Ibrahim \& Hemayed, } \\
2015\end{array}$ & $\begin{array}{l}\text { It was aimed to present evidence of } \\
\text { the cloud computing adoption to the } \\
\text { education system at universities and } \\
\text { higher education institutions. }\end{array}$ & SLR & 27 \\
\hline Brabra et al., 2016 & $\begin{array}{l}\text { It was aimed to present a wholistic } \\
\text { glance of new ways to apply semantic } \\
\text { technologies in cloud computing } \\
\text { technologies. }\end{array}$ & LR & 36 \\
\hline $\begin{array}{c}\text { Bayramusta \& Nasir, } \\
2016\end{array}$ & $\begin{array}{l}\text { The main purpose was to analyze the } \\
\text { evolution of cloud computing in progress } \\
\text { of time. }\end{array}$ & SLR & 236 \\
\hline Lynn et al., 2016 & $\begin{array}{l}\text { By using descriptive and synthetic } \\
\text { analysis, it was aimed to understand the } \\
\text { open source cloud simulation platforms. }\end{array}$ & SLR & 256 \\
\hline Solms \& Willet, 2016 & $\begin{array}{l}\text { A literature review has been carried } \\
\text { out on resources that can help prepare } \\
\text { assurance evidence within the scope of } \\
\text { IT senior management authority while } \\
\text { applying IT. }\end{array}$ & LR & 33 \\
\hline
\end{tabular}


Table 1. Continued

\begin{tabular}{|c|c|c|c|}
\hline Author and Year & Research Focus & $\begin{array}{l}\text { Research } \\
\text { Type }\end{array}$ & No. of Papers \\
\hline Yu et al., 2017 & $\begin{array}{l}\text { It was aimed to make contribution to } \\
\text { the understanding of cloud computing } \\
\text { security by presenting an explanatory } \\
\text { literature review in terms of information } \\
\text { security discipline. }\end{array}$ & $\begin{array}{l}\text { Descriptive } \\
\text { Literature } \\
\text { Research }\end{array}$ & 74 \\
\hline Mrhaouarh et al., 2018 & $\begin{array}{l}\text { The studies about cloud computing } \\
\text { adoption for developing countries } \\
\text { that depending on TOE studies were } \\
\text { reviewed. }\end{array}$ & SLR & 40 \\
\hline Senyo et al., 2018 & $\begin{array}{l}\text { The main purpose was to examine the } \\
\text { cloud computing evolution over time. }\end{array}$ & LR & 285 \\
\hline Salleh et al., 2018 & $\begin{array}{l}\text { Literature review on cloud computing } \\
\text { and SMEs, has been made including } \\
\text { adoption and post adoption stages. }\end{array}$ & SLR & 39 \\
\hline $\begin{array}{c}\text { Mohammed Banu et } \\
\text { al., } 2018\end{array}$ & $\begin{array}{l}\text { This study aimed to define and evaluate } \\
\text { empirical findings on the advantages and } \\
\text { drawbacks of Cloud Computing adoption } \\
\text { in the context of education. }\end{array}$ & SLR & 20 \\
\hline Pisirir et al., 2019 & $\begin{array}{c}\text { The existing state of the SEM literature } \\
\text { in the cloud computing field was } \\
\text { examined. }\end{array}$ & SLR & 96 \\
\hline $\begin{array}{c}\text { Ibrahim \& Hemayed, } \\
2019\end{array}$ & $\begin{array}{l}\text { The studies about the integration } \\
\text { between Trusted Computing and IaaS } \\
\text { have been surveyed. }\end{array}$ & SLR & 86 \\
\hline Novais et al., 2019 & $\begin{array}{l}\text { The aim of this study is to analyze } \\
\text { previous researches that examined the } \\
\text { Cloud Computing and Supply Chain } \\
\text { Integration. }\end{array}$ & SLR & 100 \\
\hline Al-Ahmad et al., 2019 & $\begin{array}{c}\text { This study provided a systematic } \\
\text { literature review about the penetration } \\
\text { testing in Cloud Computing mobile } \\
\text { applications. }\end{array}$ & SLR & 30 \\
\hline Sheikh et al., 2019 & $\begin{array}{l}\text { This study focused on reviewing studies } \\
\text { related with cloud computing security } \\
\text { and resource scheduling and identifying } \\
\text { the research gap. }\end{array}$ & SLR & NA \\
\hline Klaib et al., 2021 & $\begin{array}{l}\text { This study discussed the eye tracking } \\
\text { techniques and applications with a focus } \\
\text { on modern approaches such as machine } \\
\text { learning, Internet of Things and cloud } \\
\text { computing. }\end{array}$ & LR & 180 \\
\hline This Study & $\begin{array}{c}\text { Our study provides a SLR for cloud } \\
\text { computing literature from the business } \\
\text { point of view between the years of } 2014 \\
\text { and } 2019 .\end{array}$ & SLR & 141 \\
\hline
\end{tabular}


Table 2. Included and Excluded Criteria

\begin{tabular}{|c|c|c|}
\hline \multicolumn{3}{|r|}{ Explanation of the Criterion } \\
\hline \multirow{4}{*}{ Excluded } & Non- Full Text & Articles with only have title, abstract or keywords and full text is not available. \\
\hline & \multirow{3}{*}{ Not related } & Non-academic texts \\
\hline & & $\begin{array}{l}\text { Studies not examining cloud technologies from an administrative and organizational } \\
\text { perspective }\end{array}$ \\
\hline & & Studies not examining cloud computing technologies. \\
\hline \multirow{3}{*}{ Included } & \multirow{3}{*}{$\begin{array}{l}\text { Less Related } \\
\text { Closely Related }\end{array}$} & Studies that the concept of cloud is used only as an example. \\
\hline & & $\begin{array}{l}\text { Cloud computing in terms of management has not been examined but some of cloud } \\
\text { computing results or examples in terms of management has been given. }\end{array}$ \\
\hline & & $\begin{array}{l}\text { The cloud, whose main concept is not cloud computing. } \\
\text { Studies dedicated to all research efforts explicitly and specifically for cloud } \\
\text { computing. }\end{array}$ \\
\hline
\end{tabular}

distinguished and then, considering the inclusion and exclusion criteria detailed in Table 2, nonEnglish, non-academic publications were eliminated. Then, the first screening process was completed by reading the titles, abstracts and by briefly reviewing the full texts of articles (Step 4.).

\section{DATA ANALYSES AND RESULTS}

As far as the electronic databases were considered, 68\% (96 papers) of the articles were obtained from the Web of Science database. 18\% (25 papers) were obtained from Science Direct and 14\% (20 papers) from Scopus databases.

\subsection{Journal Analysis}

When the journals in which the articles published were analyzed, it has been found out that studies examining the cloud computing technologies from the perspective of business and management have found to published in 90 different journals. $77.77 \%$ of them (70 journals) have 2018 Thomson Reuter Impact Factor (IF). Figure 2 shows Future Generation Computer Systems (a Netherlands journal), International Journal of Accounting Information Systems (an England journal), and Journal of Enterprise Information Management (an England journal) as the three journals with the highest impact factor among 25 journals. $31.1 \%$ of the journals published more than one studies dealing with cloud computing technologies from business point of view.

As shown in Figure 3, 49\% of the journals were published in the subject area of Business, Management and Accounting. In addition, the subject areas of Management Science and Operations Research (\%14) and Computer Science (\%14) were the second most studied fields.

Table 3. Collection of the papers process

\begin{tabular}{|l|c|c|c|}
\hline & Web of Science & Scopus & Science Direct \\
\hline Step 1 & 12,332 & 91,916 & 108,555 \\
\hline Step 2 & 754 & 3,384 & 1,702 \\
\hline Step 3 & 308 & 797 & 423 \\
\hline Step 4 & 91 & 24 & 20 \\
\hline
\end{tabular}




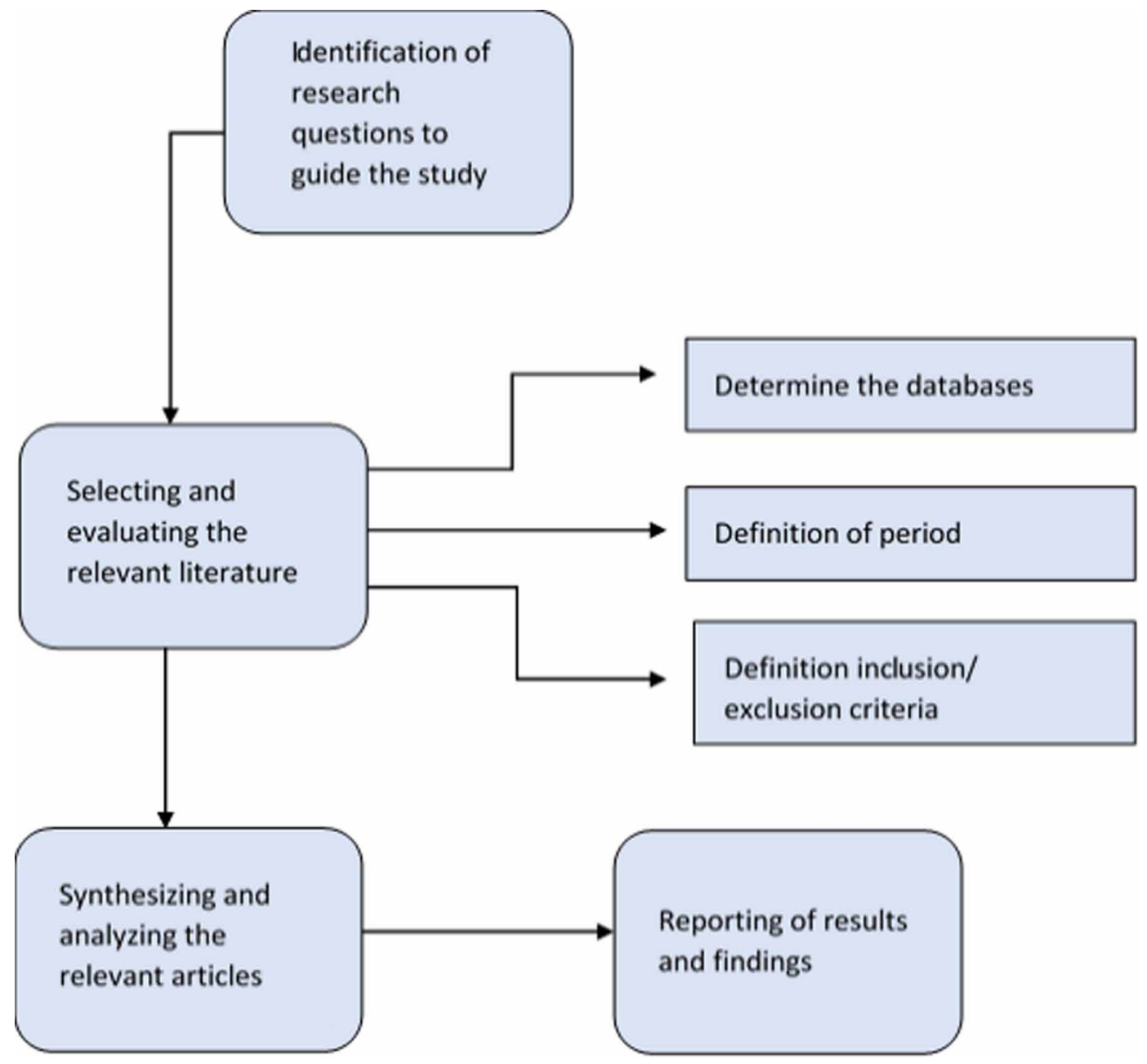

\subsection{Analysis By Year}

As can be seen from the Figure 4 studies on cloud computing technologies have increased sharply since 2015. The number of studies reached its peak in 2017. This may be related to the emergence of concept of the Industry 4.0 in 2011. The cloud computing concept is one of the most essential components of the 4th Industrial Revolution.

\subsection{Author Analysis}

Table 4 demonstrates the number of authors in each paper and their proportions. Considering the selected studies, the total number of authors is 422 . It has been observed that articles related to cloud computing technologies have more than 1 author. Approximately 30\% of the articles (43 papers) written have 3 authors and $28 \%$ of them have 2 authors (39 papers). The proportion of the papers that have more than 3 authors (4, 5, 6 and 7 authors) is $30 \%$. 
Figure 2. Analysis of Journal Articles

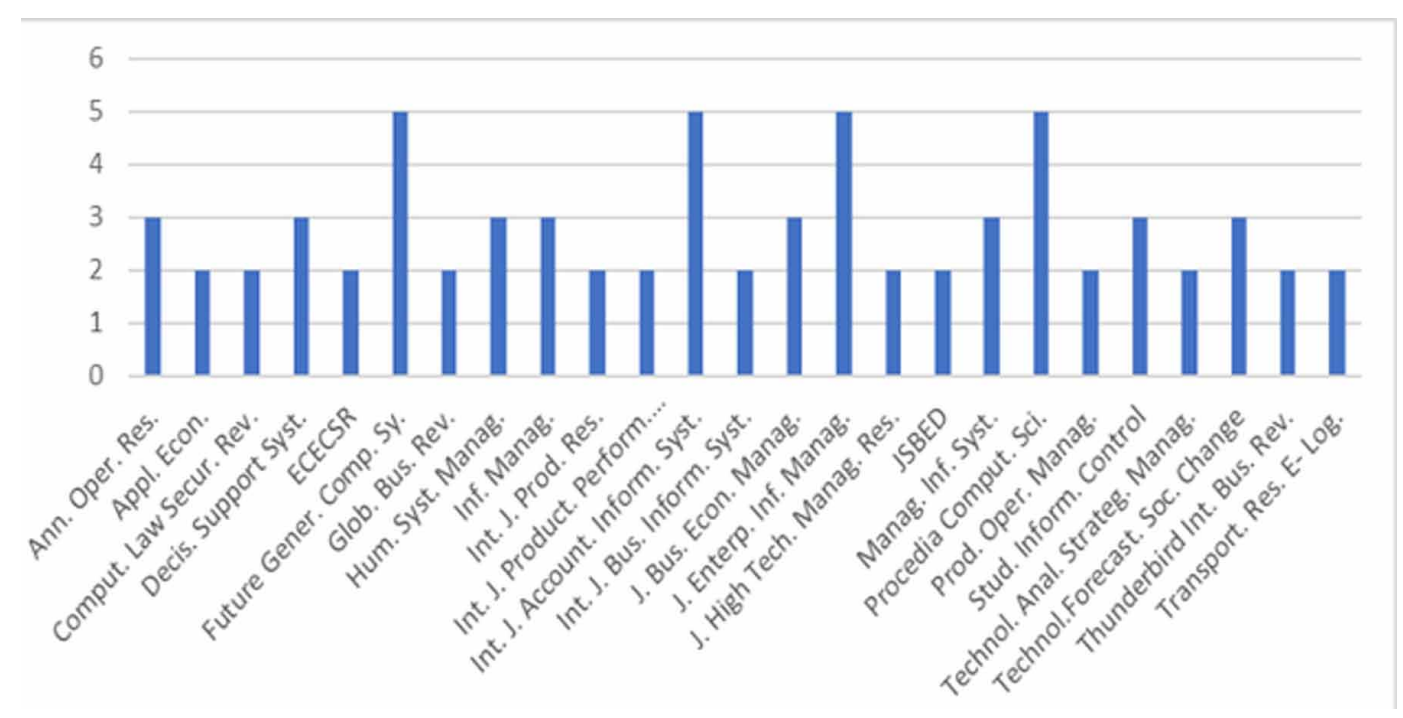

Figure 3. Journal Categorization based on each different journal with IF

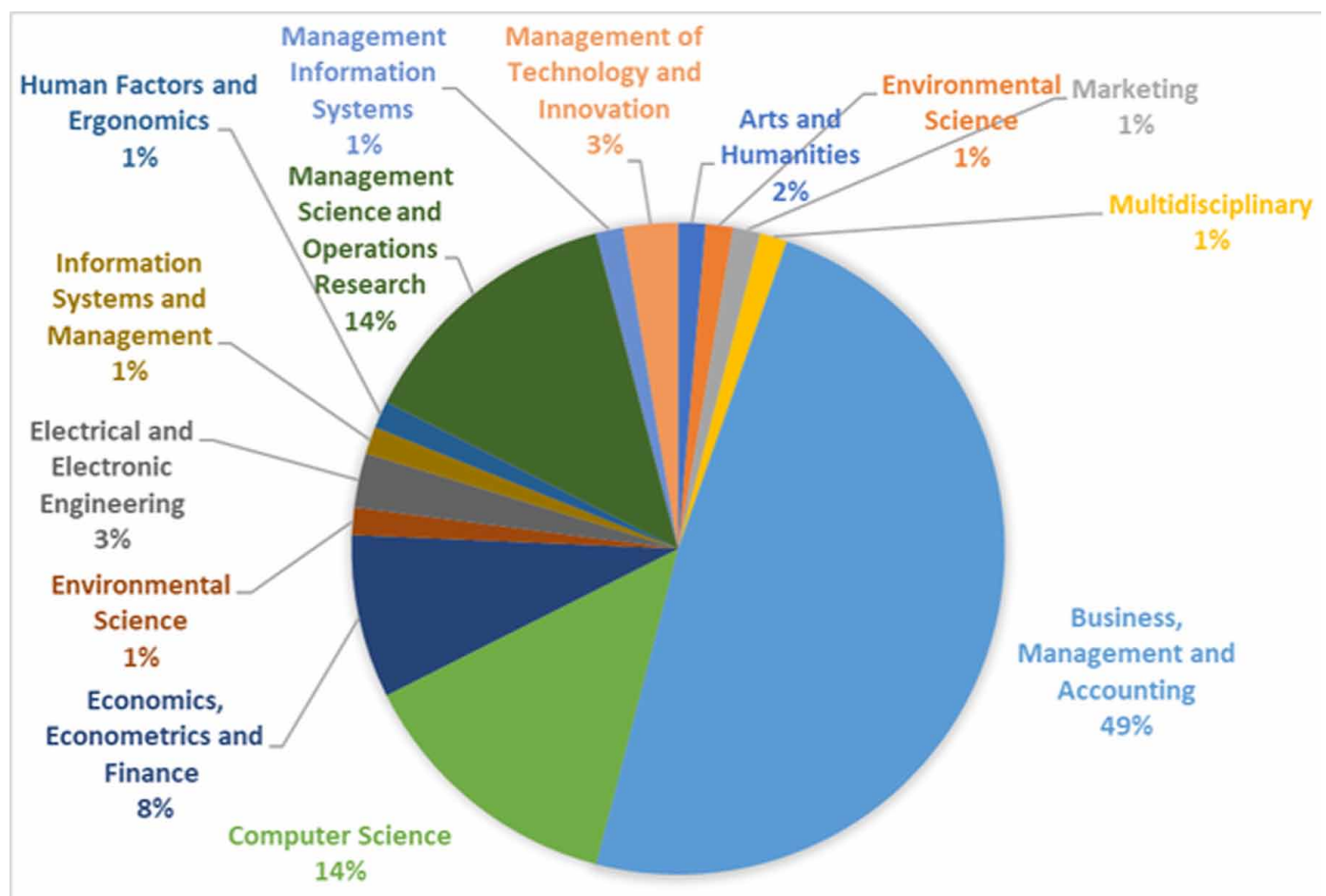




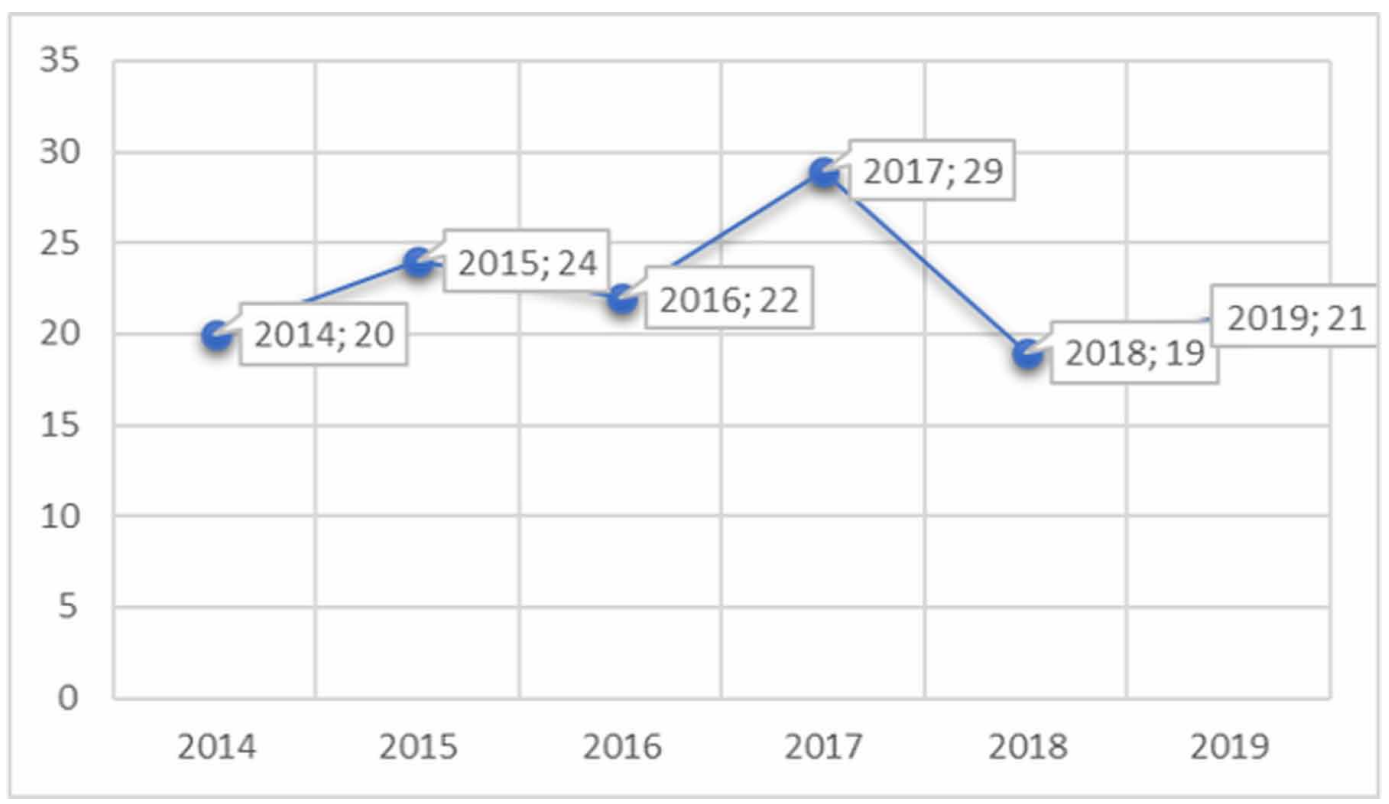

\subsection{Methodological Analysis of The Papers}

The first distinction is the basic methodological approaches that are used in the relative papers, which are classified as experimental and conceptual contributions. It was found that $40 \%$ (54 papers) of the studies were conceptual and 60\% (82 papers) were experimental studies and it can be seen from Figure 5, that more empirical studies have been carried out in recent years. When the empirical studies were examined in detail, $16.1 \%$ of them were found to have qualitative and $83.9 \%$ have quantitative research design.

In the studies that qualitative approaches were used, in depth interviews were conducted in 18 papers (51.4\%) and remaining papers were based on case studies and qualitative methods (48.6\%). In quantitative papers, questionnaire tools were commonly used and, in some papers, $(8.7 \%)$ databases were used to collect data. The questionnaires have often been conducted online and sent by e-mail or shared in social media (Such as Linked in or Twitter). The response rate was found to be high in most

Table 4. Analysis of Articles by Number of Authors

\begin{tabular}{|c|c|c|}
\hline \# of Authors & \# of Articles & Relative Frequency(\%) \\
\hline 1 & 17 & 12.06 \\
\hline 2 & 39 & 27.66 \\
\hline 3 & 43 & 30.50 \\
\hline 4 & 21 & 14.89 \\
\hline 5 & 15 & 10.64 \\
\hline 6 & 3 & 2.13 \\
\hline 7 & 3 & 2.13 \\
\hline Total & $\mathbf{1 4 1}$ & $\mathbf{1 0 0}$ \\
\hline
\end{tabular}




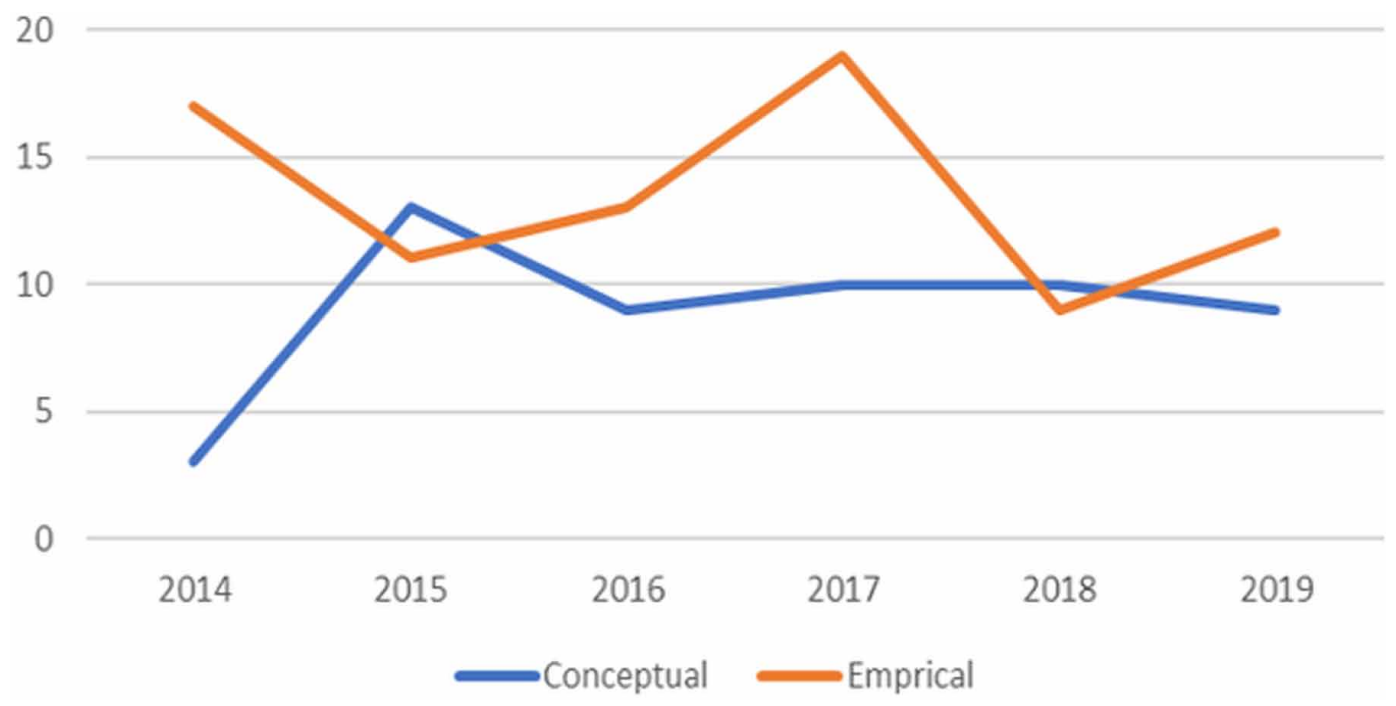

of the papers. The surveys were conducted usually in a single country (i.e., USA, Australia, India, China, Turkey, Brazil and Slovenia) and only three of them were conducted in several countries (i.e., USA and Turkey; USA and Australia; Germany, France, Italy, Poland, Spain and UK).

When the conceptual studies were deeply examined, it was found that the studies were based on two different research designs as review studies and studies that construct a model or a framework. In 46 papers $(85.2 \%)$, a model has been constructed. Some of them used case studies with their models or exemplified the models and/ or frameworks. Different review techniques (i.e., systematic literature review, portfolio review or literature review) have been used in the remaining of the conceptual studies.

\subsection{Analysis of Keywords}

The keyword analysis of the included articles provided an overview about the focus of the papers, areas of research, and which areas of cloud computing focus more on business or managerial aspects. In total 532 keywords were collected and then these keywords were grouped different related clusters. For instance, "Technology Adoption", "Cloud Computing Adoption", "Adoption Readiness", and "Cloud Computing Adoption Framework" keywords were grouped into a cluster of Adoption.

The collected keywords were analyzed quantitatively. The total cluster number was 64 . The most used cluster was "Cloud Computing" (113 times) that cover $21.25 \%$ of the total keywords. As shown in Figure 6, out of the "Cloud Computing" cluster, the top 5 clusters (Figure 6.) are "Adoption" (32 keywords), "Innovation and Technology" (26 keywords), "Information Technology" (24 keywords), "Small and Medium Enterprises" (18 keywords), and "Technology Acceptance" (14 keywords).

\subsection{Analyses of References}

The analyses of references comprise both frequencies of references in general and frequency of references that include "Cloud Computing" in their titles. Figure 7 indicates the papers that were most cited (424 times) is Gangwar et al. (2015)'s study. This study aims to integrate the TAM and TOE models in the frame of cloud computing adoption in organizations. After that, the second most cited article (271 times) were found to be "Cloud computing adoption framework: A security framework for business clouds". This article also highlighted the "Cloud Computing Adoption Framework" in businesses (Chang et al., 2016). 


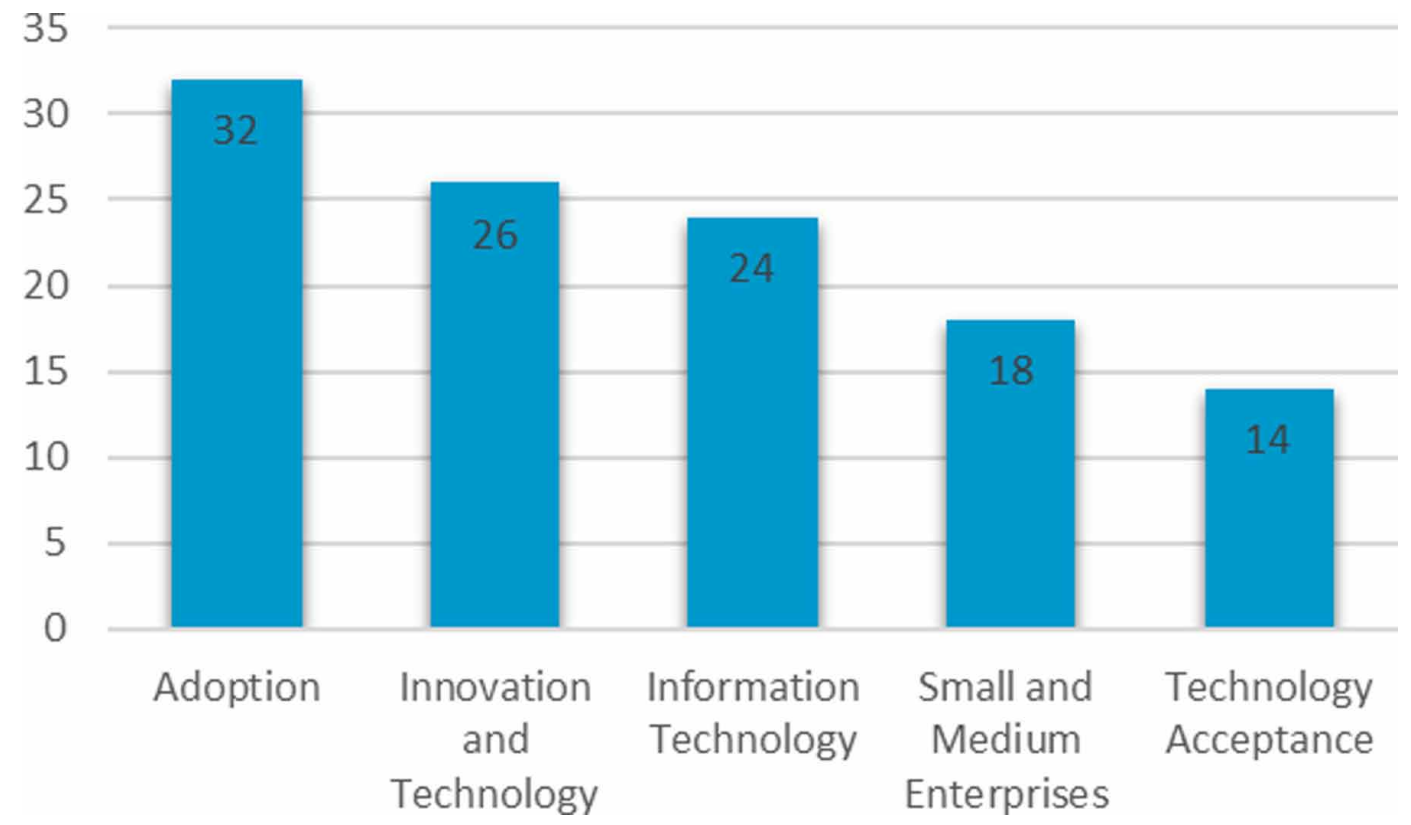

Figure 7 demonstrates that the references that include the "cloud computing" term in the titles. This can provide a comprehensive explanation about the common agreed Cloud Computing citations. 2 papers included "adoption" in their titles in the first reference analysis (Figure 7.) and in the second one, there were 4 papers, which include "adoption" in their titles (Figure 8.). This frequency analysis showed that the most cited papers were about "adoption". The remaining references were cited 3.9 times on average (including "cloud computing" in the titles).

\subsection{The Word Frequency Analysis}

As can be seen in the Table 5, first column indicated the top 25 most frequent words that were used in the included papers. The second and third columns represent the frequency and document proportion of the words (For instance, the word "service(s)" was used in $\% 99$ of the related documents). The last three columns represent the top 3 words that were combined with the in the first column.

Based on the combinations with top 3 co-occurrence words, meaningful phrases were composed. Firstly, commonly known terms that are related with cloud computing were cloud service, cloud computes service, technology adoption, innovation adoption, information technology, technology acceptance, service provider, cloud security, information security, and information technology. This measurement can represent the commonly used research areas.

Table 6 represents the top 10 words combinations (limited three words), their frequency and document proportion of the word. The most frequent word combination was used in $63.62 \%$ of the documents (984 times), second most frequent combination was "cloud computing adoption" and the fourth one, "adopt cloud compute" (244 times) was also related with adoption. That means the subject of the adoption is one of the top topics in cloud computing studies in organization level. The fifth most used combination is "supply chain management" is used $27.69 \%$ of the included documents (166 times) and the last most used combination is also "supply chain integration" (144 times). This shows that the cloud computing systems are important in supply chains. It also demonstrates that the integration of these systems into supply chains is the topic most studied topic. 


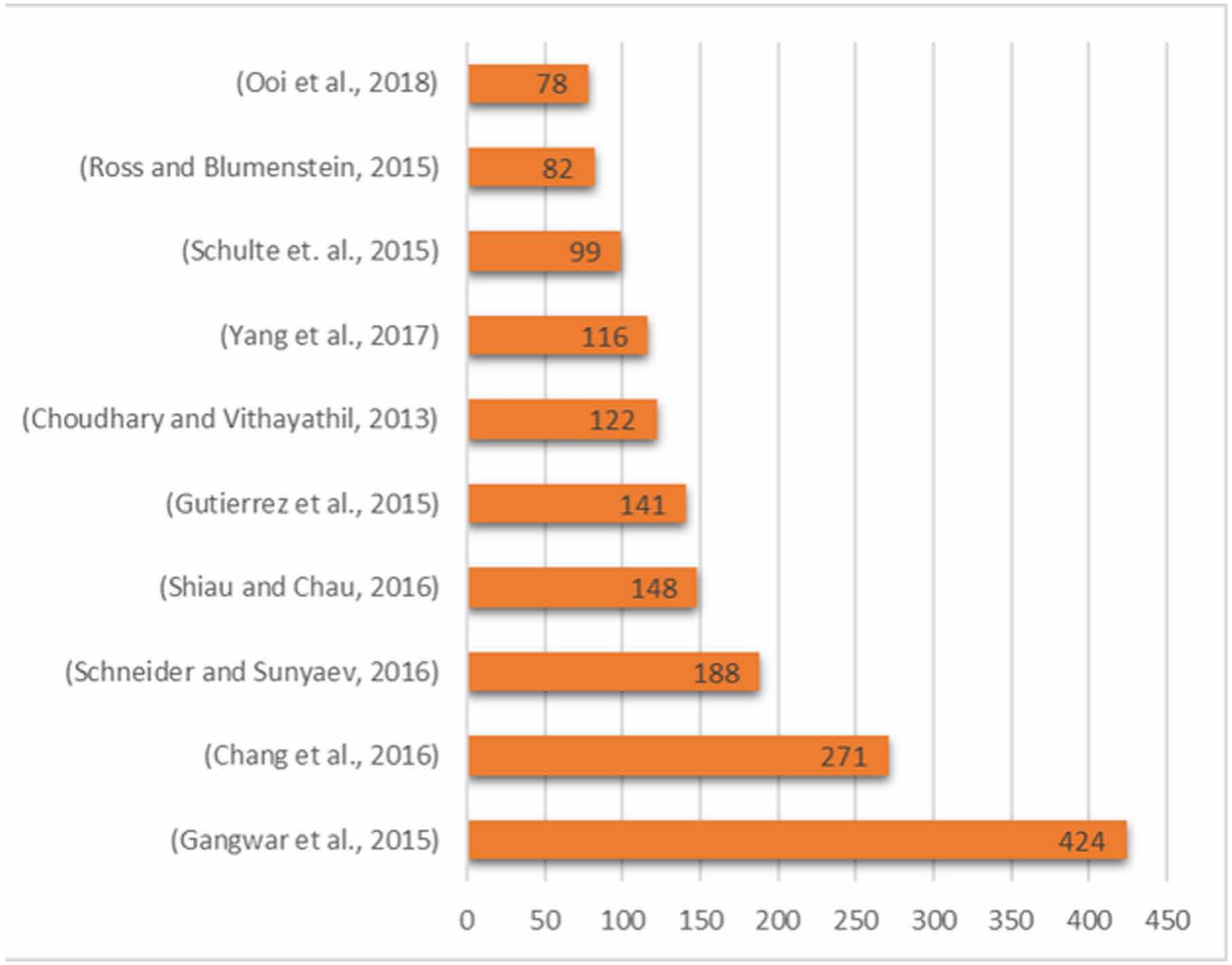

\subsection{Analysis of Research Area}

In this section we analyzed the papers in terms of their research area in general terms. As a result of the analysis, the business activities that used cloud computing and the most used research areas have been emphasized. Moreover, this analysis would be useful to determine the business subjects that have not get enough attention.

As can be seen in the Figure 9, finance and accounting is the most studied area (26\%) in the management literature of cloud computing. After that, the second most studied area is management $(23 \%)$. In the following part of this section, these research areas are to be analyzed in detail.

\subsubsection{Finance and Accounting}

In Finance and Accounting, according to Figure 10, most of the papers studied financial planning, budgeting, pricing, treasury, and investment. When the studies on pricing were examined in detail, it was seen that Chen et al. (2019) studied choosing optimal price schemes for cloud providers. Basu et al. (2015) provided a guideline for cloud providers for pricing their offerings, while Javed et al. (2016) presented a new dynamic pricing method to cloud providers. The general purpose of the papers about pricing is to provide a guideline for pricing to cloud providers. Pricing has an important effect on organizations' profit, revenue, and market share and therefore, these studies can help the cloud providers to make a good decision about their pricing strategy. When the studies on investment have been deeply analyzed, most of the studies were found to investigate whether the transformation from 
Figure 8. Frequency of references that include "Cloud Computing" in their titles

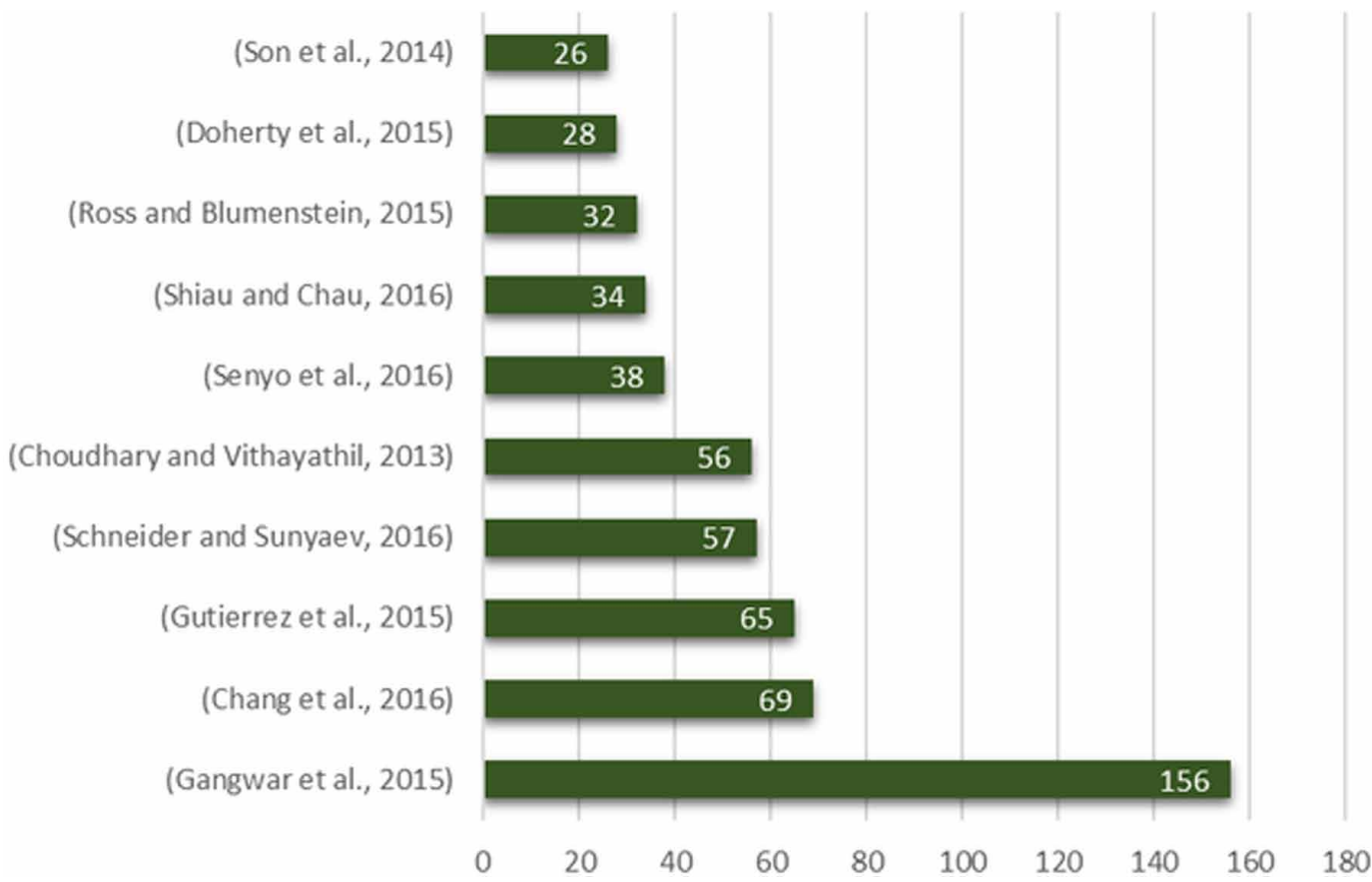

classic IT infrastructure to cloud was beneficial or not (see. Maresova et al., 2017) and evaluate the suitability of cloud computing adoption (Kumar et al., 2017).

\subsubsection{Management}

As can be seen in Figure 11, the human resources management is the most studied subject. Embedded digital skill in human resources and better understanding the information communication technology are acquired for cloud adoption. Some papers consider the effects of information communication technology on cloud computing adoption (Hadhri et al., 2017; Kyriakou \& Loukis, 2019). The second most studied subject is reliability and security. Organizations want to transfer their data to cloud to reduce cost and increase efficiency, but security issues remain challenge to adopt cloud computing (Chang et al., 2016). Surprisingly, although it is known that the adoption of cloud computing provides a more environmentally friendly and efficient business structure in the long term (Marston et al., 2011), the sustainability subject has not got enough attention in recent years.

\subsubsection{Production and Operations Management}

As presented in Figure 12, supply chain is the most studied topic in the production and operation area. The studies dealing with the supply chain integration is mostly in the context of small and medium sized enterprises (Raut et al., 2018; Manuel et al., 2019). Cloud computing integration on supply chains can help managers to observe, plan and evaluate supply chain processes. The second most studied topic is Production, Operations and Quality. In these studies, the new way of production (i.e., smart factories) is a vital subject (Nodehi et al., 2017; Ooi et al., 2018). Cloud computing contributes to the transformation of traditional manufacturing into a more digital one. Therefore, the integration of cloud computing and investing in cloud are critical decisions for manufacturers. Raut et al. (2019) and Haug et al. (2016) worked on cloud adoption decisions in manufacturing. 
Table 5. Top 25 most frequent words related to Cloud Computing related word combinations

\begin{tabular}{|c|c|c|c|c|c|}
\hline \multirow[b]{2}{*}{ Word } & \multirow[b]{2}{*}{ Frequency } & \multirow[b]{2}{*}{$\begin{array}{l}\% \text { (relative } \\
\text { frequency) }\end{array}$} & \multicolumn{3}{|c|}{ Word Combinations } \\
\hline & & & 1st & 2nd & 3rd \\
\hline service(s) & 9276 & 99.231 & cloud & compute & provider(s) \\
\hline adoption & 3646 & 83.077 & intention & innovation & service(s) \\
\hline technology(s) & 3424 & 95.385 & information & compute & acceptance \\
\hline resource(s) & 3289 & 97.692 & compute & cloud & allocation \\
\hline provider(s) & 3042 & 92.308 & service(s) & cloud & SaaS \\
\hline system(s) & 2684 & 99.231 & information & support & computer \\
\hline security & 1723 & 80.769 & information & datum & cloud \\
\hline support & 1713 & 93.077 & management & decision & system(s) \\
\hline application & 1695 & 96.923 & cloud & base & service(s) \\
\hline user(s) & 1692 & 95.385 & cloud & end & acceptance \\
\hline performance & 1681 & 86.923 & business & firm & operational \\
\hline level & 1671 & 93.077 & service & agreement & restriction(s) \\
\hline innovation(s) & 1408 & 69.231 & technological & technology & service(s) \\
\hline software & 1291 & 95.385 & engineer & enterprise & application(s) \\
\hline access & 1218 & 93.846 & network & date & gain \\
\hline network(s) & 1217 & 90.769 & social & access & value \\
\hline framework & 918 & 84.615 & TOE & theoretical & conceptual \\
\hline platform & 830 & 83.846 & cloud & compute & deployment \\
\hline development & 729 & 91.538 & service(s) & software & technological \\
\hline IaaS & 662 & 65.385 & cloud & PaaS & service(s) \\
\hline Computer & 531 & 74.615 & system(s) & science & generation \\
\hline Internet & 524 & 83.077 & base & service(s) & connection \\
\hline computer & 418 & 75.385 & system(s) & science & generation \\
\hline $\mathrm{PaaS}$ & 391 & 60.000 & IaaS & provider & SaaS \\
\hline algorithm & 377 & 30.769 & genetic & schedule & propose \\
\hline Software & 340 & 70.000 & engineer(s) & enterprise & application(s) \\
\hline
\end{tabular}

As a result of the analysis made so far, it has been seen that $\mathrm{CC}$ adoption is one of the most studied topics. It has been observed that 55 studies are dealing with cloud computing adoption and technology acceptance. There are also studies found on these issues with different subjects and viewpoints. 34\% of the studies focused on cloud computing adoption in small and medium-sized enterprises, which have an important place in most of the developing economies, even though they face with many challenges, such as inability to access appropriate technologies, lack of qualified personnel etc. 
Table 6. Top 10-word combinations in the papers

\begin{tabular}{|l|c|c|}
\hline \multicolumn{2}{|c|}{ The Combinations of Three Words } \\
\hline Words & Count & Relative Frequency (\%) \\
\hline cloud compute service & 984 & 64.62 \\
\hline cloud compute adoption & 740 & 45.38 \\
\hline cloud service provider & 268 & 52.31 \\
\hline adopt cloud compute & 244 & 40.00 \\
\hline supply chain management & 166 & 27.69 \\
\hline top management support & 162 & 21.54 \\
\hline security and privacy & 153 & 33.85 \\
\hline cloud compute technology & 149 & 33.85 \\
\hline decision support system & 145 & 40.00 \\
\hline supply chain integration & 144 & 9.23 \\
\hline
\end{tabular}

\section{DISCUSSIONS AND MANAGERIAL IMPLICATIONS}

With the emergence of Industry 4.0, technologies such as artificial intelligence, cloud computing and big data have been used effectively by organizations. Recently, cloud computing has become a mature structure that is widely used by companies. Organizations move their workloads and sensitive data to the cloud to integrate cloud computing into their systems, which brings some risks and concerns (cloud security, secure access, identity management). Using multiple cloud service providers in organizations and managing the situation safely and effectively are one of the most important issues. The vast majorities of companies are concerned about cloud security and cloud data loss (Crow Research Partner, 2018; Bommadevara et al., 2018).

Cloud computing is nowadays converting into an issue that has become the main element of many companies' business models. Cloud computing provides a cost advantage to businesses, as many systems can be set up in different environments outside of their systems due to the cloud computing infrastructure. It increases the scalability of systems and this affects a company's success, reputation, and profitability. The use of cloud computing technologies helps businesses to react and adapt quickly to the market needs.

One of the most important effects of the cloud is leverage. There are many disruptive technologies (technologies that will cause major transformations such as artificial intelligence, internet of things, big data, autonomous robots etc.) that come along with Industry 4.0, which are expected to improve many industries. If these technologies can be combined with the cloud, the benefit they offer can be seen easily. For instance, when the Internet of Things is combined with the cloud, the data received from the devices can be instantly distributed to many places, allowing real-time decision making. On the other hand, the cloud computing can show a leverage effect by adding value to all destructive and innovative technologies related with Industry 4.0.

In this paper, we obtained some results from general and detailed data analysis corresponding to research questions of the included papers. The results summarize the current research attempts; most demanded and examined research topics and the research gap in cloud computing literature from managerial perspective. The current literature review reveals the fact that cloud computing is an intersecting theme of many interdisciplinary fields (Information communication technologies, supply chain, management, logistics, engineering, marketing, etc.). In addition to the research gaps and future research paths arising from answering previous research questions, some areas of business are particularly interesting in the cloud computing. 
Figure 9. Research Area of the Papers

- Finance and Accounting a Marketing

- Production and Operations $\square$ Management

- Other

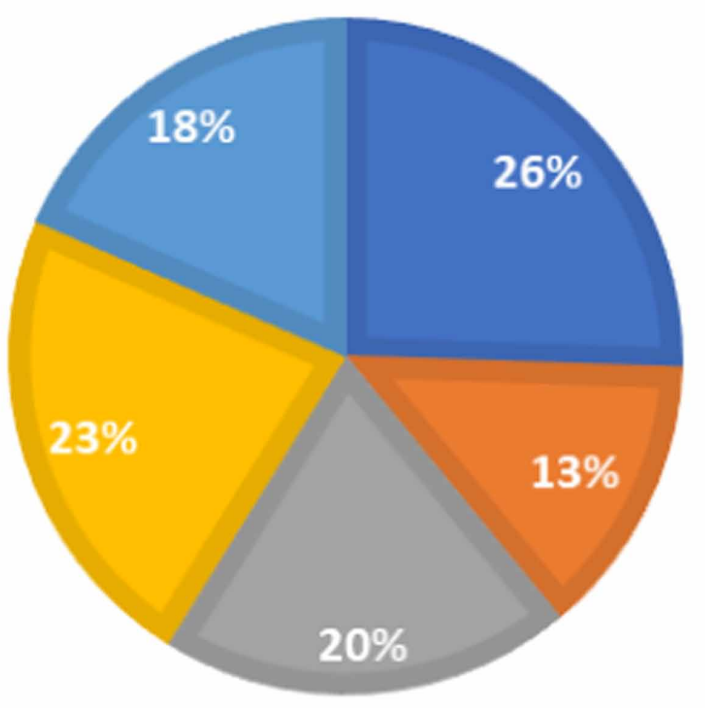

Figure 10. Finance and Accounting Papers

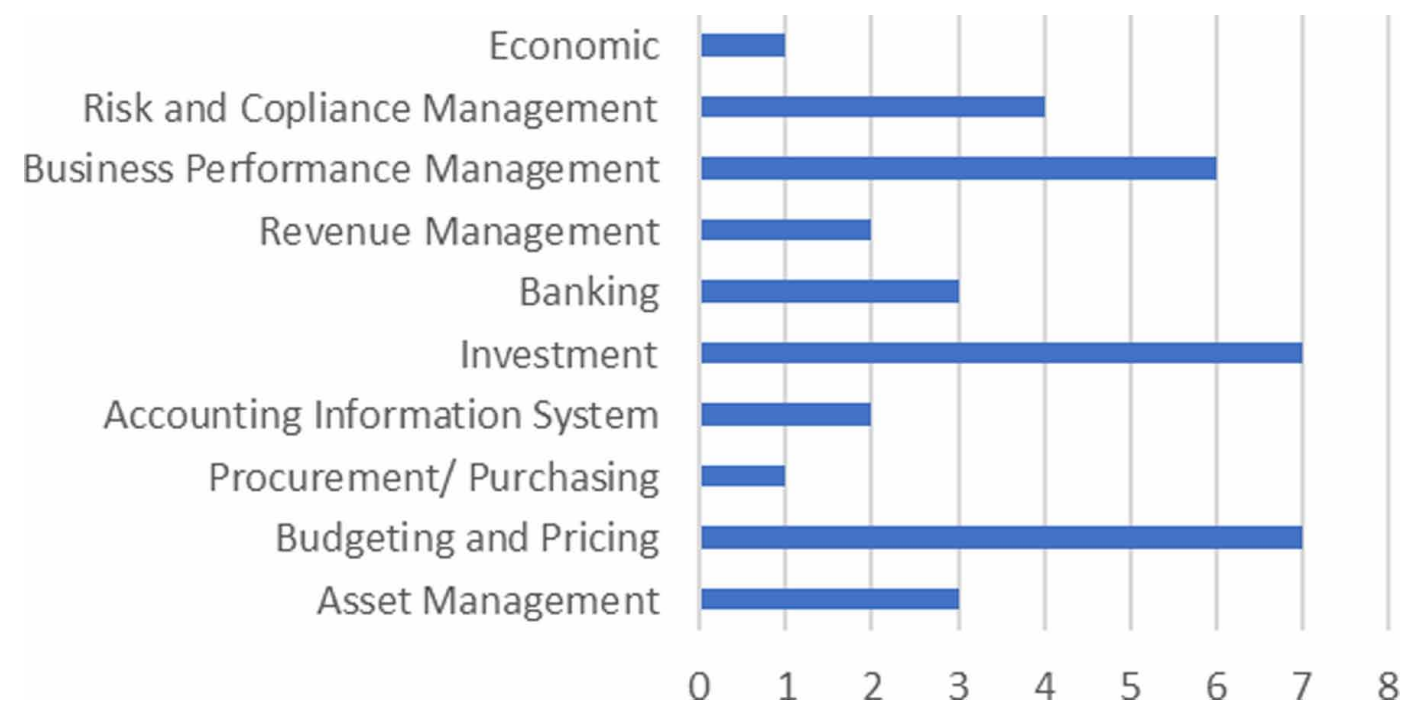


Figure 11. Management Papers

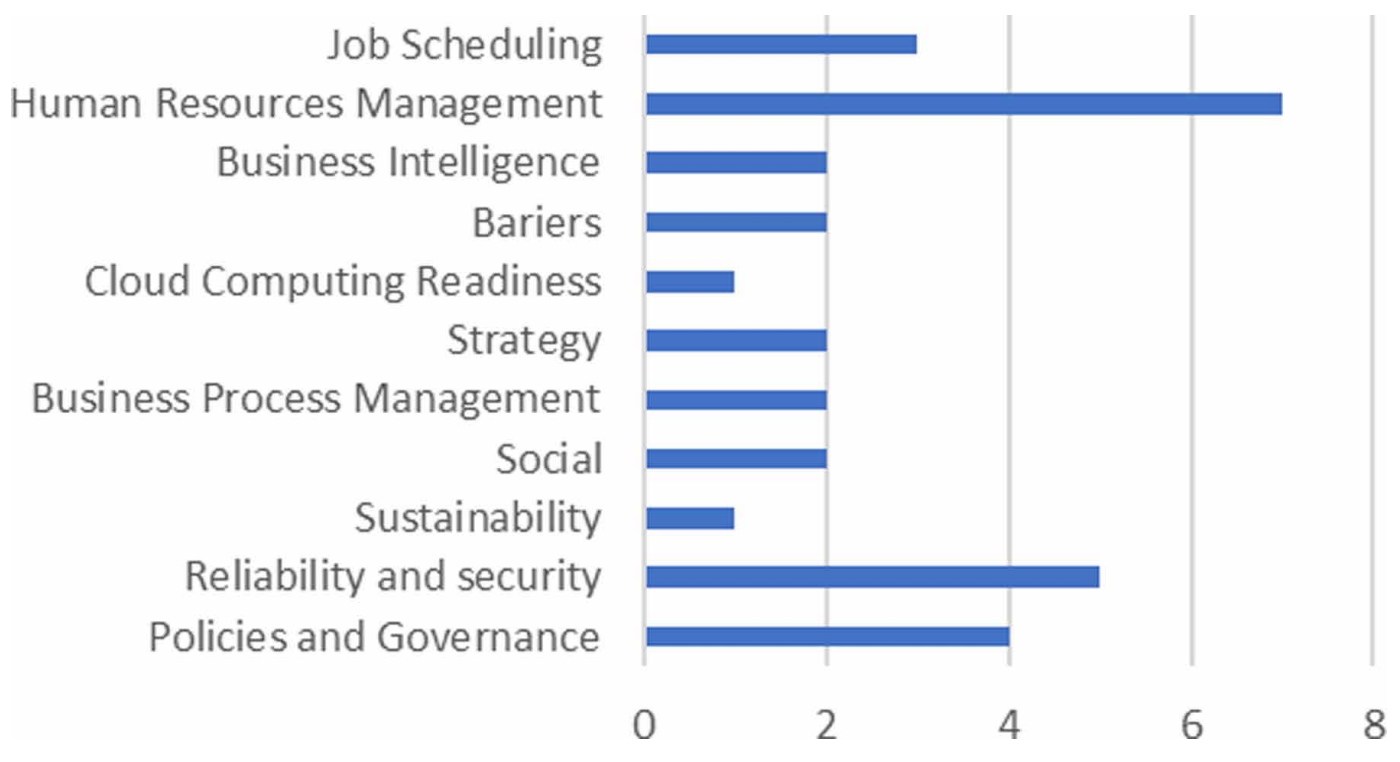

Figure 12. Production and Operation Management Papers

Production, Operations and Quality

Supply Chain

Logistic

Organisations Decisions and Intentions

Attitude towards Cloud

Innovation Adoption

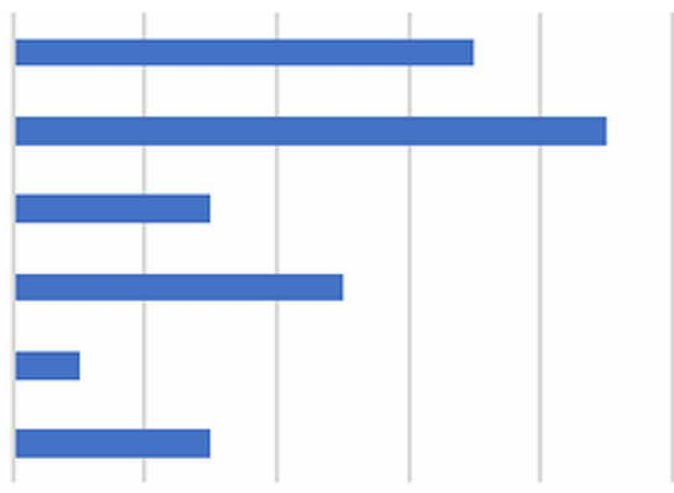

0

2

4

6

8

10 
Table 7. Some application areas of cloud computing

\begin{tabular}{|l|l|l|l|}
\hline \multicolumn{1}{|c|}{ Reference } & \multicolumn{1}{c|}{ Year } & \multicolumn{1}{c|}{ Company } & \multicolumn{1}{c|}{ Proposed Solution } \\
\hline $\begin{array}{l}\text { (1) Hauff et al., (2014) } \\
\text { (2) Mladenow et al., } \\
\text { (2015) }\end{array}$ & 2014 & Market Maker & $\begin{array}{l}\text { Market Maker is an intermediary between cloud users } \\
\text { and cloud providers. It provides a cloud platform that is } \\
\text { called Cloud Market. }\end{array}$ \\
\hline $\begin{array}{l}\text { (3) Suherman \& } \\
\text { Simatupang, (2017) }\end{array}$ & 2017 & Bina Simar Amity & $\begin{array}{l}\text { Cloud Pilot is a German cloud solution provider for } \\
\text { construction companies, and it offers mobile cloud base } \\
\text { applications. }\end{array}$ \\
\hline $\begin{array}{l}\text { (4) Dumitrache et al., } \\
\text { (2017) }\end{array}$ & 2017 & ICIPRO project & $\begin{array}{l}\text { ICIPRO is a cloud-based solution is to automate } \\
\text { companies. It provides data storage, Infrastructure as a } \\
\text { Service (IaaS) and virtualizes cloud resources. }\end{array}$ \\
\hline $\begin{array}{l}\text { (5) Nieuwenhuis et al., } \\
\text { (2018) }\end{array}$ & 2018 & $\begin{array}{l}\text { Microsoft } \\
\text { Dynamics AX }\end{array}$ & $\begin{array}{l}\text { It was generated to operate Microsoft's cloud computing } \\
\text { platform (Azure). Azur provides building deploying, } \\
\text { managing applications and it offers to access online } \\
\text { tools, frameworks and services. }\end{array}$ \\
\hline
\end{tabular}

As can be seen in the Table 7, there are only 5 papers (3.7\%) that offer the cases of application. Four of them used case studies and one of them was a project for a specific country (ICIPRO). It was discovered that (1) focused on the applicability of a cloud market in an inter-organizations context and how organizations were achieved standardized IT resources in future (Hauff et al., 2014). (2) The advantage for cloud-based real estate companies is the ability to regulate IT-based resources supply to unstable IT-based resources demand in the short term (Mladenow et al., 2015). (3) The cloud solution performs well when it complements other existing systems in companies such as ERP (Suherman \& Simatupang, 2017). (4) The overall objective of the ICIPRO project is the modernization, development and optimization of public services offered to citizens through a Cloud Computing infrastructure (Dumitrache et al., 2017). (5) Microsoft is responsible to operate the software smoothly in the Cloud, and standardized software optimizes sustainability and lowers cost in return (Nieuwenhuis et al., 2018).

Despite the increasing importance of cloud applications, there are few practical studies on this subject in the literature. It can be concluded from this analysis that companies and academicians rarely interact with each other, although there is a growing interest in this issue from both sides.

\section{CONCLUSION}

Industry 4.0 has been one of the most important subjects of academic research since 2011. It has basically 11 components (Internet of things, big data, cyber security, augmented realty, cloud computing, simulation, horizontal and vertical integration, additive manufacturing, autonomous robots, cyber physical systems and smart factories). As a result of the research, it has been seen that there is no systematic literature review about some components of Industry 4.0 from business perspective. In the future, researchers can conduct systematic literature review using smart factories, augmented realty, system integration and autonomous robots keywords in terms of business, supply chain management, manufacturing and sustainability perspective.

Our study contributes to the current cloud computing literature between the years of 2014 and 2019. Methodologically, our study reveals an organized collection of knowledge accumulated in this field. From a research perspective, we propose a classification across the spectrum of business aspects in cloud computing. The main purpose of this research is to systematically review and analyze the studies undertaken between the years 2014 and 2019 that dealing with cloud computing from business viewpoint. This study indicates literature gaps, reveals current research efforts and presents a research 
agenda for future studies. It has revealed the importance of cloud computing from both theoretical and practical perspectives. Firstly, the articles related to the cloud computing in managerial field and the prominent journals were listed. Then, the categories of the journals were examined. A general list of keywords has been made and then keywords have been clustered specifically. The analysis of the keywords provided important information on the topics that are currently been studied related to cloud computing. The most frequently used words in the articles and the statistics of using words used together were also very useful in determining the current study areas, research focus and some neglected subjects in the literature. Moreover, our analysis showed that "adoption" is the area that is most studied in the cloud computing research and the researchers can review the cloud computing literature systematically in terms of "adoption".

In addition to the research gaps as a result of the analysis made, some other areas of management are found to be particularly interesting in the cloud computing field. Systematic literature analysis has shown that technology acceptance, supply chain management and technology (innovation) from managerial aspect are frequently studied. As a result of the analysis, it was seen that the subject of adoption of cloud computing has been studied from different perspectives in the literature. The issue of cloud adoption in SMEs has attracted a lot of attention. The supply chain is the topic that is most studied by researchers related to production. Surprisingly, cloud computing technologies have not gained enough attention in terms of sustainability.

Similar to Karunakaran et al. (2015)'s study, which showed that the most studied themes are pricing, market, sourcing, and adoption on cloud computing till 2014, our study has shown that adoption is still one of the most studied topics in cloud computing literature between the years 2014 and 2019. Additionally, our study analyzes the relevant literature deeper in terms of the business research areas and reveals that human resources management; supply chain management, production and operations management, quality management, investment, and budgeting are also among the rising topics in cloud computing literature.

The purpose of this study is not only to reveal the gap in the cloud computing literature, but also the tendencies, and interest towards this topic from managerial perspective. Our study also offers a research agenda for the cloud computing literature in terms of business viewpoint. The findings of this study may contribute to management endeavoring to implement cloud computing within companies to foster decision making processes. Hence, the outcomes of this study may further act as a guideline for managers in global context especially from information management perspective. Therefore, this study can support the efforts of the business people towards strengthening the competitive advantages of their companies via cloud computing.

There are some limitations of the study. The conference proceedings, Ph.D. theses, and articles published after the year of 2019 were excluded. This review covers the accessible papers on cloud computing from the business perspective that were published in the years between 2014 and 2019 in three databases (Web of Science, Science Direct and Scopus). Because of the search criteria limits in English language, existing cloud computing papers published in other languages are excluded. However, expanding this systematic review of the literature may be interesting for future research.

This systematic literature review indicated the current state of cloud computing literature from business perspectives. Many multi-criteria decision-making methods were used in the existing literature. Future studies can focus on new models, methods, numerical studies and approaches. Thus, more robust strategies can be developed for integrating cloud computing technologies into companies with different organization levels, supply chains and logistics networks. With the increase in cloud computing investment in recent years, the adoption of cloud computing has become an important topic. Companies have started to be concerned with cloud security and sensitive data protection. As a result, cloud security is an important issue to be studied in the future both practically and academically. In future studies, quality management and its sub-topics can be studied more in terms of cloud computing. Moreover, the future research may focus on cloud adoption on larger enterprises. 
Some factors affecting the adoption such as trust, security, and top management support can be further studied in the future. Moreover, sustainability is a trendy topic in the relevant literature, which has not been enough studied. Therefore, environmental and social sustainability concerns can be addressed further in the cloud literature. Furthermore, as mentioned before, there are few practical studies in the relevant literature, so more empirical and practical research needs to be carried out by utilizing various theories and models. For instance, the adoption of cloud computing in various industries and sectors (e.g., tourism and manufacturing) and different economies can be analyzed by employing various quantitative and qualitative approaches. In addition, investigating the relationships among service quality, trust, loyalty, and respect for customer privacy for success in CRM systems can be considered in the future. 


\section{REFERENCES}

Al-Ahmad, A. S., Kahtan, H., Hujainah, F., \& Jalab, H. A. (2019). Systematic Literature Review on Penetration Testing for Mobile Cloud Computing Applications. IEEE Access : Practical Innovations, Open Solutions, 7 , 173524-173540. doi:10.1109/ACCESS.2019.2956770

Alismaili, S. Z., Li, M., Shen, J., Huang, P., He, Q., \& Zhan, W. (2020). Organisational-level assessment of cloud computing adoption: Evidence from the Australian SMEs. Journal of Global Information Management, 28(2), 73-89. doi:10.4018/JGIM.2020040104

Basu, S., Chakraborty, S., \& Sharma, M. (2015). Pricing cloud services-The impact of broadband quality. Omega, 50, 96-114. doi:10.1016/j.omega.2014.07.006

Bayramusta, M., \& Nasir, V. A. (2016). A fad or future of IT? A comprehensive literature review on the cloud computing research. International Journal of Information Management, 36(4), 635-644. doi:10.1016/j. ijinfomgt.2016.04.006

Benslimane, Y., Plaisent, M., Bernard, P., \& Bahli, B. (2014, December). Key challenges and opportunities in cloud computing and implications on service requirements: Evidence from a systematic literature review. In 2014 IEEE 6th International Conference on Cloud Computing Technology and Science (pp. 114-121). IEEE.

Bommadevara, N., Del Miglio, A., \& Jansen, S. (2018). Cloud adoption to accelerate IT modernization. Digitial McKinsey: Insights, 1-8.

Borodako, K., Berbeka, J., \& Rudnicki, M. (2021). Technology Used in Knowledge Management by Global Professional Event Services. Journal of Global Information Management, 29(1), 145-163. doi:10.4018/ JGIM.2021010108

Brabra, H., Mtibaa, A., Sliman, L., Gaaloul, W., \& Gargouri, F. (2016, June). Semantic web technologies in cloud computing: a systematic literature review. In 2016 IEEE International Conference on Services Computing (SCC) (pp. 744-751). IEEE. doi:10.1109/SCC.2016.102

Chang, V., Kuo, Y. H., \& Ramachandran, M. (2016). Cloud computing adoption framework: A security framework for business clouds. Future Generation Computer Systems, 57, 24-41. doi:10.1016/j.future.2015.09.031

Chen, F., Bai, X., \& Liu, B. (2011, May). Efficient service discovery for cloud computing environments. In International Conference on Computer Science and Information Engineering (pp. 443-448). Springer. doi:10.1007/978-3-642-21411-0_72

Chen, S., Lee, H., \& Moinzadeh, K. (2019). Pricing schemes in cloud computing: Utilization-based vs. reservationbased. Production and Operations Management, 28(1), 82-102. doi:10.1111/poms.12893

Chen, Y., Duan, L., \& Zhang, W. (2020). Effect of user involvement in supply chain cloud innovation: A game theoretical model and analysis. Journal of Global Information Management, 28(1), 23-38. doi:10.4018/ JGIM.2020010102

Deloitte. (2015). Industry 4.0-Challenges and Solutions fort the Digital Transformation and Use of Exponential Technologies. Deloitte.

Deloitte. (2020). Covid-19 Impact: IT Due Diligence Considerations Technology Enablement for the Future. Author.

Dumitrache, M., Sandu, I. E., \& Barbu, D. C. (2017). An Integrated Cloud Computing Solution for Romanian Public-Sector Entities: ICIPRO Project. Studies in Informatics and Control, 26(4), 481-487. doi:10.24846/ v26i4y 201712

Durao, F., Carvalho, J. F. S., Fonseka, A., \& Garcia, V. C. (2014). A systematic review on cloud computing. The Journal of Supercomputing, 68(3), 1321-1346. doi:10.1007/s11227-014-1089-X

Gagic, D., \& Jones, M. (2019). Accelerating Your Journey to Hybrid Cloud. IBM Cloud, 1-23.

Gangwar, H., Date, H., \& Ramaswamy, R. (2015). Understanding determinants of cloud computing adoption using an integrated TAM-TOE model. Journal of Enterprise Information Management, 28(1), 107-129. doi:10.1108/ JEIM-08-2013-0065 
Garza-Reyes, J. A. (2015). Lean and green-a systematic review of the state-of-the-art literature. Journal of Cleaner Production, 102, 18-29. doi:10.1016/j.jclepro.2015.04.064

Hadhri, W., Maherzi, T., \& Youssef, A. B. (2017). E-Skills and the Adoption of Cloud Computing. Thunderbird International Business Review, 59(5), 635-645. doi:10.1002/tie.21895

Hanafizadeh, P., \& Zareravasan, A. (2020). A Systematic Literature Review on IT Outsourcing Decision and Future Research Directions. Journal of Global Information Management, 28(2), 160-201. doi:10.4018/ JGIM.2020040108

Hauff, S., Huntgeburth, J., \& Veit, D. (2014). Exploring uncertainties in a marketplace for cloud computing: A revelatory case study. Journal of Business Economics, 84(3), 441-468. doi:10.1007/s11573-014-0719-3

Haug, K. C., Kretschmer, T., \& Strobel, T. (2016). Cloud adaptiveness within industry sectors-Measurement and observations. Telecommunications Policy, 40(4), 291-306. doi:10.1016/j.telpol.2015.08.003

Ibrahim, F. A., \& Hemayed, E. E. (2019). Trusted cloud computing architectures for infrastructure as a service: Survey and systematic literature review. Computers \& Security, 82, 196-226. doi:10.1016/j.cose.2018.12.014

Ibrahim, M. S., Salleh, N., \& Misra, S. (2015, June). Empirical studies of cloud computing in education: a systematic literature review. In International Conference on Computational Science and Its Applications (pp. 725-737). Springer. doi:10.1007/978-3-319-21410-8_55

Javed, B., Bloodsworth, P., Rasool, R. U., Munir, K., \& Rana, O. (2016). Cloud market maker: An automated dynamic pricing marketplace for cloud users. Future Generation Computer Systems, 54, 52-67. doi:10.1016/j. future.2015.06.004

Jula, A., Sundararajan, E., \& Othman, Z. (2014). Cloud computing service composition: A systematic literature review. Expert Systems with Applications, 41(8), 3809-3824. doi:10.1016/j.eswa.2013.12.017

Kagermann, Wahlster, \& Helbig. (2013). Recommendations for Implementing the Strategic Initiative INDUSTRIE 4.0. Berlin: Industrie 4.0 Working Group of Acatech.

Karunakaran, S., Krishnaswamy, V., \& Rangaraja P, S. (2015). Business view of cloud. Management Research Review, 38(6), 582-604. doi:10.1108/MRR-01-2014-0021

Klaib, A. F., Alsrehin, N. O., Melhem, W. Y., Bashtawi, H. O., \& Magableh, A. A. (2020). Eye Tracking Algorithms, Techniques, Tools, and Applications with an Emphasis on Machine Learning and Internet of Things Technologies. Expert Systems with Applications, 114037.

Kumar, D., Samalia, H. V., \& Verma, P. (2017). Exploring suitability of cloud computing for small and mediumsized enterprises in India. Journal of Small Business and Enterprise Development, 24(4), 814-832. doi:10.1108/ JSBED-01-2017-0002

Kyriakou, N., \& Loukis, E. N. (2019). Do strategy, processes, personnel and technology affect firm's propensity to adopt cloud computing? Journal of Enterprise Information Management, 32(3), 517-534. doi:10.1108/ JEIM-06-2017-0083

Lal, P., \& Bharadwaj, S. S. (2020). Understanding the Drivers of Cloud-Based Service Adoption and Their Impact on the Organizational Performance: An Indian Perspective. Journal of Global Information Management, 28(1), 56-85. doi:10.4018/JGIM.2020010104

Lehrig, S., Eikerling, H., \& Becker, S. (2015, May). Scalability, elasticity, and efficiency in cloud computing: A systematic literature review of definitions and metrics. In Proceedings of the 11th International ACM SIGSOFT Conference on Quality of Software Architectures (pp. 83-92). doi:10.1145/2737182.2737185

Lu, Y., Papagiannidis, S., \& Alamanos, E. (2018). Internet of Things: A systematic review of the business literature from the user and organisational perspectives. Technological Forecasting and Social Change, 136, 285-297. doi:10.1016/j.techfore.2018.01.022

Lynn, T., Gourinovitch, A., Byrne, J., Byrne, P. J., Svorobej, S., Giannoutakis, K. M., . . Morrison, J. P. (2017, April). A Preliminary Systematic Review of Computer Science Literature on Cloud Computing Research using Open Source Simulation Platforms. In CLOSER (pp. 537-545). doi:10.5220/0006351805650573 
Manuel Maqueira, J., Moyano-Fuentes, J., \& Bruque, S. (2019). Drivers and consequences of an innovative technology assimilation in the supply chain: Cloud computing and supply chain integration. International Journal of Production Research, 57(7), 2083-2103. doi:10.1080/00207543.2018.1530473

Marešová, P., \& Soběslav, V. (2017). Effective evaluation of cloud computing investment: application of cost benefit method analysis. Business Administration and Management, 135-144.

Marston, S., Li, Z., Bandyopadhyay, S., Zhang, J., \& Ghalsasi, A. (2011). Cloud computing-The business perspective. Decision Support Systems, 51(1), 176-189. doi:10.1016/j.dss.2010.12.006

Mcsi, M. I. E. T. E. (2009). Configurability in SaaS (software as a service) applications. In Proceedings of 2 nd Annual Conference on India Software Engineering Conference (pp. 19-26). Academic Press.

Mell, P., \& Grance, T. (2009). Perspectives on cloud computing and standards. National Institute of Standards and Technology (NIST). Information Technology Laboratory.

Mladenow, A., Novak, N. M., \& Strauss, C. (2015). Mobility for 'Immovables'-clouds supporting the business with real estates. Procedia Computer Science, 63, 120-127. doi:10.1016/j.procs.2015.08.320

Moher, D., Liberati, A., Tetzlaff, J., \& Altman, D. G. (2009). Preferred Reporting Items for Systematic Reviews and Meta-Analyses: The PRISMA Statement. PLoS Medicine, 6(7), 264-269. doi:10.1371/journal.pmed.1000097 PMID:19621072

Mrhaouarh, I., Okar, C., Namir, A., \& Chafiq, N. (2018, November). Cloud Computing adoption in developing countries: A systematic literature review. In 2018 IEEE International Conference on Technology Management, Operations and Decisions (ICTMOD) (pp. 73-79). IEEE. doi:10.1109/ITMC.2018.8691295

Müller, S. D., Holm, S. R., \& Søndergaard, J. (2015). Benefits of cloud computing: Literature review in a maturity model perspective. Communications of the Association for Information Systems, 37(1), 42. doi:10.17705/1CAIS.03742

Nieuwenhuis, L. J., Ehrenhard, M. L., \& Prause, L. (2018). The shift to Cloud Computing: The impact of disruptive technology on the enterprise software business ecosystem. Technological Forecasting and Social Change, 129, 308-313. doi:10.1016/j.techfore.2017.09.037

Nodehi, T., Jardim-Goncalves, R., Zutshi, A., \& Grilo, A. (2017). ICIF: An inter-cloud interoperability framework for computing resource cloud providers in factories of the future. International Journal of Computer Integrated Manufacturing, 30(1), 147-157.

Novais, L., Maqueira, J. M., \& Ortiz-Bas, Á. (2019). A systematic literature review of cloud computing use in supply chain integration. Computers \& Industrial Engineering, 129, 296-314. doi:10.1016/j.cie.2019.01.056

Okoli, C., \& Schabram, K. (2010). A guide to conducting a systematic literature review of information systems research. Working Papers on Information Systems, 1-49.

Ooi, K. B., Lee, V. H., Tan, G. W. H., Hew, T. S., \& Hew, J. J. (2018). Cloud computing in manufacturing: The next industrial revolution in Malaysia? Expert Systems with Applications, 93, 376-394. doi:10.1016/j. eswa.2017.10.009

Piccarozzi, M., Aquilani, B., \& Gatti, C. (2018). Industry 4.0 in management studies: A systematic literature review. Sustainability, 10(10), 3821. doi:10.3390/su10103821

Pickering, C., \& Byrne, J. (2014). The benefits of publishing systematic quantitative literature reviews for PhD candidates and other early-career researchers. Higher Education Research \& Development, 33(3), 534-548. do i:10.1080/07294360.2013.841651

Pişirir, E., Uçar, E., Chouseinoglou, O., \& Sevgi, C. (2019). Structural equation modeling in cloud computing studies: A systematic literature review. Kybernetes, 49(3), 982-1019. doi:10.1108/K-12-2018-0663

Raut, R., Priyadarshinee, P., Gardas, B. B., Narkhede, B. E., \& Nehete, R. (2018). The incident effects of supply chain and cloud computing integration on the business performance. Benchmarking, 25(8), 2688-2722. doi:10.1108/BIJ-07-2017-0170 
Raut, R. D., Gardas, B. B., Narkhede, B. E., \& Narwane, V. S. (2019). To investigate the determinants of cloud computing adoption in the manufacturing micro, small and medium enterprises. Benchmarking, 26(3), 990-1019. doi:10.1108/BIJ-03-2018-0060

Rimal, B. P., Jukan, A., Katsaros, D., \& Goeleven, Y. (2011). Architectural requirements for cloud computing systems: An enterprise cloud approach. Journal of Grid Computing, 9(1), 3-26. doi:10.1007/s10723-010-9171-y

Salleh, N. A., Hussin, H., Suhaimi, M. A., \& Ali, A. M. (2018, July). A Systematic Literature Review of Cloud Computing Adoption and Impacts among Small Medium Enterprises (SMEs). In 2018 International Conference on Information and Communication Technology for the Muslim World (ICT4M) (pp. 278-284). IEEE. doi:10.1109/ ICT4M.2018.00058

Senyo, P. K., Addae, E., \& Boateng, R. (2018). Cloud computing research: A review of research themes, frameworks, methods and future research directions. International Journal of Information Management, 38(1), 128-139. doi:10.1016/j.ijinfomgt.2017.07.007

Sheikh, A., Munro, M., \& Budgen, D. (2019). Systematic Literature Review (SLR) of resource scheduling and security in cloud computing. International Journal of Advanced Computer Science and Applications, 10(4). Advance online publication. doi:10.14569/IJACSA.2019.0100404

Suherman, A. G., \& Simatupang, T. M. (2017). The network business model of cloud computing for endto-end supply chain visibility. International Journal of Value Chain Management, 8(1), 22-39. doi:10.1504/ IJVCM.2017.082684

Wang, R., \& Ying, S. (2018). SaaS software performance issue identification using HMRF-MAP framework. Software, Practice \& Experience, 48(11), 2000-2018. doi:10.1002/spe.2607

$\mathrm{Xu}, \mathrm{X}$. (2012). From cloud computing to cloud manufacturing. Robotics and Computer-integrated Manufacturing, 28(1), 75-86. doi:10.1016/j.rcim.2011.07.002

Yu, Z., Wang, Z., Wang, N., Su, X., \& Ge, S. (2017). A Descriptive Literature Review about Cloud Computing Security Research in the IS Discipline. Destech Transactions on Computer Science and Engineering, 421-432.

Mine Omurgonulsen is an associate professor of Operations Management in the Department of Business Administration of Hacettepe University, Ankara, Turkey. She obtained her Doctorate from the same Department in 2007. Her current research areas include digital transformation and Quality Management. She has published papers in TQM and Business Excellence and Production Planning and Control.

Merve Ibis is a research assistant in the Department of Business Administration of Baskent University, Ankara, Turkey. She is getting her master's from the Production Management and Quantitative Methods Department at Hacettepe University. Her current research areas include operations research and production management. He graduated from Izmir American College in 1998.

Yigit Kazancoglu received his B.S. degree from Eastern Mediterranean University, Dept. of Industrial Engineering as a Honour student. He graduated from Coventry University, England, MBA and Izmir University of Economics MBA programs as a High Honour student, respectively in 2003 and 2004. Kazancoglu has received his PhD. at Ege University (Production \& Operations Management). He was an Assistant Professor Dr. 2008-2013; and Associate Professor Dr. 2014-2016 in Izmir University of Economics, Dept. of Business Administration. Between December 2016 - May 2019 he worked as Associate Professor Dr. in Yasar University, International Logistics Management Department. In May 2019, he is assigned as Full Professor Dr. He was the director of Izmir University of Economics Continuing Education Center (EKOSEM) between 2009-2014. He is the head of Logistics Management Department in Yasar University since 2017. His research areas are Operations Management, Management Information Systems, Total Quality Management, Supply Chain Management, MCDM multi criteria decision making methods.

Pretty Singla has completed her UG and PG from Kurukshetra University, India. Ms. Pretty is working in the field of Cloud Computing, Artificial Neural Network, Database Management; Decision Making and Modelling. She has a teaching experience of two years. She is committed to do and promote high quality research and teaching. 